\title{
PELATIHAN SOFTWARE AUTODESK INVENTOR DALAM MENINGKATKAN KOMPETENSI SISWA KEJURUAN
}

\author{
Alviani Hesthi Permata Ningtyas ${ }^{1}$, Benny Arif Prambudiarto ${ }^{2}$, Kholidia Ayunaning $^{3}$, Muhammad \\ Khabib $^{4}$, Rafli Pramudia Putra ${ }^{5}$, Mohammad Dafid Cahyono ${ }^{6}$. \\ Program Studi Teknik Mesin, Fakultas Teknik, Universitas Muhammadiyah Gresik \\ Email: alvianihesthi@umg.ac.id
}

\begin{abstract}
Abstrak
Peningkatan kualitas sumber daya manusia di bidang pendidikan kejuruan menjadi fokus tujuan dalam kegiatan pengabdian masyarakat ini. Melalui pelatihan software inventor, kualitas sumber daya manusia pada sekolah kejuruan SMK PGRI 1 Gresik dan SMK Maskumambang 1 Dukun diberikan pemahaman dan pengetahuan tentang software Inventor yang 50\% dari peserta belum pernah mengetahui software tersebut sebelumnya. Dengan metode ceramah, tanya jawab, demonstrasi dan praktek diberikan dalam penyajian materi. Hasil dari pelatihan software inventor ini diperoleh nilai kepuasan $87.5 \%$ dengan skala penilaian sangat baik untuk fasilitator, $87.5 \%$ untuk fasilitas dan $87.5 \%$ pemateri serta $87.5 \%$ untuk materi yang diberikan. Saran untuk pelatihan kedepannya bisa diselenggarakan dengan durasi yag lebih lama dan peserta mendapatkan buku paduan.
\end{abstract}

Kata Kunci: pengabdian masyarakat, pelatihan, software inventor, siswa kejuruan

\section{PENDAHULUAN}

Agar mampu bersaing di dunia kerja, lulusan SMK dituntut untuk menguasai pengetahuan yang selaras dengan perkembangan teknologi. Program program komputer pendukung telah banyak digunakan di sektor industri. Salah satunya adalah Autodesk INVENTOR. Program ini memiliki keunggulan semua objek dan hubungan antar geometri dapat dimodifikasi kembali meski geometrinya sudah jadi, tanpa perlu mengulang lagi dari awal. Program ini juga mampu memberikan simulasi gerak dari produk yang telah didesain serta perlengkapan untuk menganalisis kekuatannya (Seprianto, 2011).

Menanggapi masalah tersebut, kegiatan pengabdian masyarakat dilaksanakan oleh UMG dalam bentuk pelatihan program Autodesk INVENTOR. Terdapat beberapa SMK yang menjadi mitra dari pelatihan Autodesk INVENTOR yang diadakan yaitu SMK KAL 1 Surabaya, SMK PGRI 1 Gresik, SMK Maskumambang 1 dan SMK
Muhammadiyah 1 Gresik. Dengan meninjau kondisi pandemi yang sedang terjadi sehingga pelatihan (Mustakim et al., 2021)diadakan di Universitas Muhammadiyah Gresik dengan mengikuti protokol kesehatan COVID-19 dengan jumlah peserta sebanyak 15 orang. Peserta dipilih dengan dasar SMK terkait belum pernah menggunakan Autodesk INVENTOR. $73 \%$ peserta bahkan baru mengetahui terdapat program Autodesk INVENTOR ataupun program sejenisnya.

Pada fase awal penggunaannya, CAD digunakan untuk tahapan 2D. Di Indonesia sendiri, CAD mulai digunakan pada awal tahun 1980-an(Hidayat et al., 2020). Seiring dengan kemajuan teknologi, CAD kemudian berevolusi menjadi semakin banyak dan kemampuannya meningkat sehingga mampu mengolah tahapan 3D (Seprianto, 2011). Penggunaan CAD dapat ditujukan untuk mendefinisikan suatu part, menganalisis faktor - faktor dalam part, mensimulasikan kerja mekanis, dan lain lain. Proses - proses tersebut nantinya akan menghasilkan suatu basis data desain yang 
berupa data geometrik (bentuk atau visual suatu part) dan data non geometrik (bill of material, peralatan yang digunakan, dan data data pendukung yang berguna bagi pengguna basis data desain tersebut) (Turner dkk., 1993)

\section{TINJAUAN PUSTAKA}

Autodesk INVENTOR adalah sebuah program CAD (Computer Aided Design) yang dikembangkan oleh perusahaan perangkat lunak asal Amerika Serikat. Program ini merupakan pengembangan dari program AutoCAD (Automatic Computer Aided Design)(Ningtyas et al., 2021). Kelebihan yang dimiliki oleh Autodek INVENTOR meliputi

1. Kemampuan mendesain dan serta modifikasi dalam tahapan 2D maupun tahapan 3D.

2. Kemampuan dalam menyusun komponen, simulasi, dan analisis.

3. Kemampuan membuat gambar gerak dari komponen yang telah disusun.

4. Kemampuan mengubah desain part menjadi bentuk technical drawing

(Rozik,2020)

Pada program Autodesk

INVENTOR, pengguna dapat membuat sketsa 2D produk, memodelkannya menjadi 3D yang kemudian dilanjutkan dengan proses pembuatan prototipe virtual atau dapat dilanjutkan lagi hingga tahap simulasi (Pinem, 2010). Analisis yang dapat dilakukan pada program Autodesk INVENTOR seperti analisis struktur (stress analysis dan frame analysis). Stress analysis menggunakan konsep Finite Element Analysis (FEA)(Pahlawan et al., 2021) dalam pengujiannya. Prinsip kerja dari analisis ini adalah dengan memecah objek yang akan diuji menjadi elemen elemen berhingga yang saling terhubung satu dengan yang lain yang nantinya akan dikelola menggunakan perhitungan khusus oleh program sehingga memberikan hasil yang lebih akurat (Jahidin dan Manfaat,
2013). Frame analysis menggunakan prinsip mekanika teknik yang berkaitan dengan struktur truss, beam, dan frame. Data yang dimasukkan berupa data beban dan tumpuan, sedangkan hasilnya berupa diagram tegangan, regangan, dan displacement (Jahidin dan Manfaat, 2013).

\section{METODE PELAKSANAAN}

Metode dan tahapan dalam pelaksanaan pengabdian ini dapat dideskripsikan sebagai berikut:

1. Tahap Persiapan

Kunjungan ke beberapa SMK di Kabupaten Gresik khususnya Teknik Permesinan sebagai langkah survey dan observasi agar pelatihan ini sesuai dengan yang dibutuhkan oleh siswa SMK. Dilanjutkan dengan penyusunan proposal oleh tim pelaksana sesuai dengan indentifikasi permasalahan dan sasaran yang ingin dicapai.

2. Realisasi Kegiatan

Kegiatan pelatihan diselenggarakan pada hari minggu, tanggal 7 Maret 2021. Kegiatan dilaksanakan di laboratorium Supply Chain ManagementTeknik Industri, Universitas Muhammadiyah Gresik. Materi pelatihan berisi tentang pengenalan software Autodesk Inventor, Gambar 2-D dan 3-D part dan assembling.

3. Metode yang digunakan

Metode yang digunakan pada pelatihan ini yaitu ceramah, tanya jawab, demonstrasi dan praktek.

Metode ceramah dan tanya jawab diberikan saat penyajikan materi tentang pengenalan software Autodesk Inventor dan penggunakan masing-masing command utility dengan bantuan slide powerpoint.

Metode demonstrasi dan praktek langsung digunakan pemateri 


\begin{abstract}
dalam mendemonstrasikan langkah-langkah menggambar 2D dan 3-D kepada peserta pelatihan. Setelah pemateri menyajikan materi, peserta pelatihan diberikan kesempatan untuk mencoba dan menggambar sesuai dengan langkah - langkah yang telah didemonstrasikan oleh pemateri.
\end{abstract}

\section{Pertanyaan survey kepuasan}

Metode perolehan data yang digunakan yaitu dengan memberikan soal pre-test, post test dan survey kepuasan peserta seperti pada daftar pertanyaan dibawah ini. Dari jawaban peserta pada soal yang diberikan yang nantinya akan digunakan untuk menjadi acuhan pada pembahasan dan kesimpulan di penelitian ini.

Latar belakang

1 Dari mana saudara tahu tentang software inventor

2 Kendala yang dihadapi dalam baru mengetahui software inventor

3 Kendala yang dihadapi dalam belajar software inventor

Penilaian terhadap Fasilitator (panitia program)

1. Skala angka penilaian untuk fasilitator

2. Alasan memberikan penilaian untuk fasilitator

3. Saran untuk fasilitator

Penilaian terhadap fasilitas

1. Skala angka penilaian untuk fasilitas

2. Alasan memberikan penilaian untuk fasilitas

3. Saran untuk fasilitas

Penilaian terhadap Pemateri

1. Skala angka penilaian untuk Pemateri

2. Alasan memberikan penilaian untuk pemateri

3. Saran untuk pemateri
Penilaian terhadap materi

1. Skala angka penilaian untuk materi

2. Alasan memberikan penilaian untuk materi

3. Saran untuk materi

Penilaian kebermanfaatan dan keberlanjutan

1 Motivasi mengikuti pelatihan inventor di Teknik Mesin UMG

2 Apakah kegiatan pelatihan ini memberikan manfaat bagi saudara

3 Manfaat yang diperoleh setelah mengikuti pelatihan

4 Apakah sesuai tujuan saudara mengikuti pelatihan dengan hasil yang didapatkan

5 Apakah saudara bersedia mengikuti pelatihan lanjutan apabila diadakan kembali

6 Alasan menjawab pertanyaan nomer 5

\section{A. HASIL DAN PEMBAHASAN}

\section{Evaluasi akhir kegiatan}

Dalam kegiatan pelatihan software inventor ini, peserta diberikan soal dan waktu untuk mengerjakan soal pre-test sebelum memulai kegiatan dan soal post-test setelah mengikuti kegiatan pelatihan. Berdasarkan dari hasil soal pre-test dan post-test didapatkan hasil yang signifikan. Sebelum mengikuti pelatihan, peserta belum mengetahui gambaran mengenai software inventor. Setelah mengikuti pelatihan, hasil posttest peserta terdapat peningkatan kemampuan pengetahuan dan keterampilan praktek. Gambar 1. menunjukan peningkatan nilai pre-test dan post-test dari peserta pelatihan. 


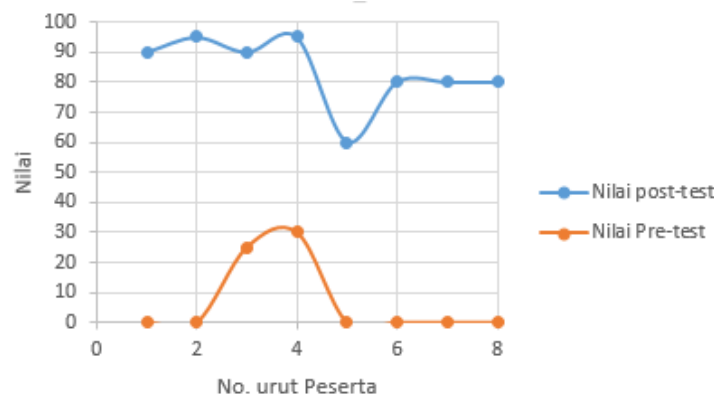

Gambar 1. Nilai Pre-test dan Post-test 2. Evaluasi kepuasan peserta

Dalam mengetahui tingkat kepuasan peserta pelatihan Inventor, peneliti menggunakan metode Kirkpatrik Level 1 dimana yang menjadi bahan survei yaitu Fasilitator, Fasilitas, Pemateri dan Materi (F2PM). Fasilitator dalam kegiatan pelatihan software inventor ini yaitu panitia yang mengurus kegiatan dari sebelum, selama dan setelah kegitan berlangsung. Fasilitas adalah bahan yang dibutuhkan peserta dalam kegiatan seperti komputer, materi slide ppt, ruangan ber-AC, soal pre-test dan post-test. Pemateri merupakan orang yang memberikan materi pada peserta pelatihan karena wawasan dan pengalaman yang memadahi untuk menyampaikan materi kepada peserta pelatihan. Materi merupakan bahan ajar yang harus disampaikan pada peserta pelatihan.

\begin{tabular}{|l|l|}
\hline Skala angka & Keterangan \\
\hline 1 & Sangat buruk \\
\hline 2 & Buruk \\
\hline 3 & Baik \\
\hline 4 & Sangat baik \\
\hline
\end{tabular}

Tabel 1. Skala angka evaluasi

Hasil kepuasan peserta terhadap kegiatan pelatihan pada faslitator dapat dilihat dalam diagram batang pada gambar 2. Dimana pada gambar 2 menunjukan nilai yang baik pada $12.5 \%$ peserta dan nilai sangat baik pada $87.5 \%$ peserta yang datang. Alasan dari peserta memberikan nilai baik dan sangat baik yaitu perhatian, ramah, sopan. Adapun saran yang diberikan peserta kepada fasilitator yaitu pelan - pelan dalam mendampingi

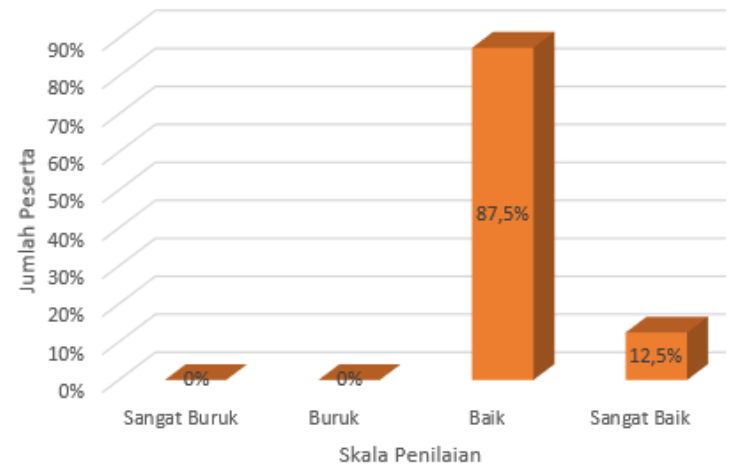

Gambar 2. Kepuasan peserta terhadap fasilitator

Hasil kepuasan peserta terhadap kegiatan pelatihan pada fasilitas dapat dilihat dalam diagram batang pada gambar 3. Dimana pada gambar 3 menunjukan nilai yang baik pada $12.5 \%$ peserta dan nilai sangat baik pada $87.5 \%$ peserta yang datang. Alasan dari peserta memberikan nilai baik dan sangat baik yaitu ruangan nyaman, bersih, rapi dan disediakan komputer setiap peserta. Adapun saran yang diberikan peserta kepada fasilitator yaitu komputer 13 tidak mendukung untuk membuat ulir dan kursi kurang nyaman.

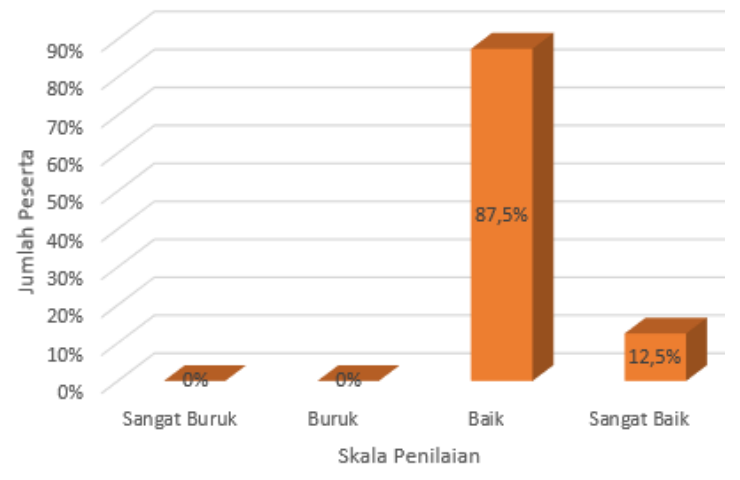

Gambar 3. Kepuasan peserta terhadap fasilitas

Hasil kepuasan peserta terhadap kegiatan pelatihan pada pemateri dapat dilihat dalam diagram batang pada gambar 4. Dimana pada gambar 4 menunjukan nilai yang baik pada $12.5 \%$ peserta dan nilai sangat baik pada $87.5 \%$ peserta yang datang. Alasan dari peserta memberikan 
nilai baik dan sangat baik yaitu penyampaian sangat jelas, bahasa cukup dimengerti, ramah, baik, sopan, sabar, menjelaskan dengan baik, sangat mudah dipahami. Adapun saran yang diberikan peserta kepada pemateri yaitu lebih lancar berbicara saat memberikan materi, pelan pelan dalam menyampaikan materi, dan lebih kreatif dalam menyampaikan materi

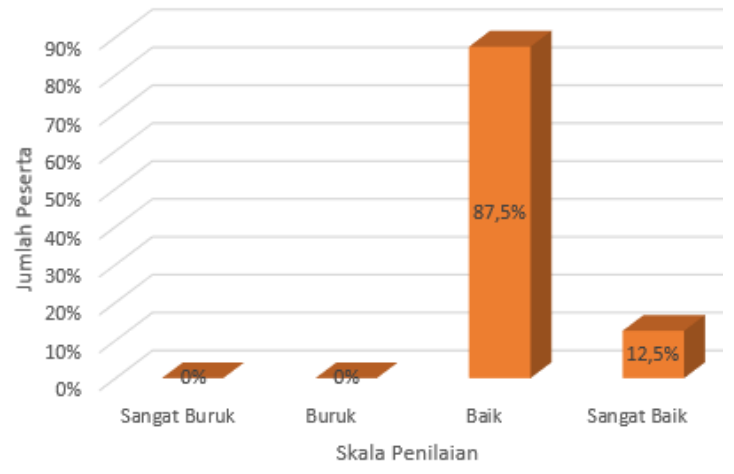

Gambar 4. Kepuasan peserta terhadap pemateri.

Hasil kepuasan peserta terhadap kegiatan pelatihan pada materi dapat dilihat dalam diagram batang pada gambar 5 . Dimana pada gambar 5 menunjukan nilai yang baik pada $87.5 \%$ peserta dan nilai sangat baik pada $12.5 \%$ peserta yang datang. Alasan dari peserta memberikan nilai baik dan sangat baik yaitu materi sangat dibutuhkan untuk peserta dalam menggambar, dijelaskan dengan rinci, materi yang diberikan lengkap menyangkup seluruh icon di software. Adapun saran yang diberikan peserta untuk materi yaitu materi diperjelas, gambar kurang banyak

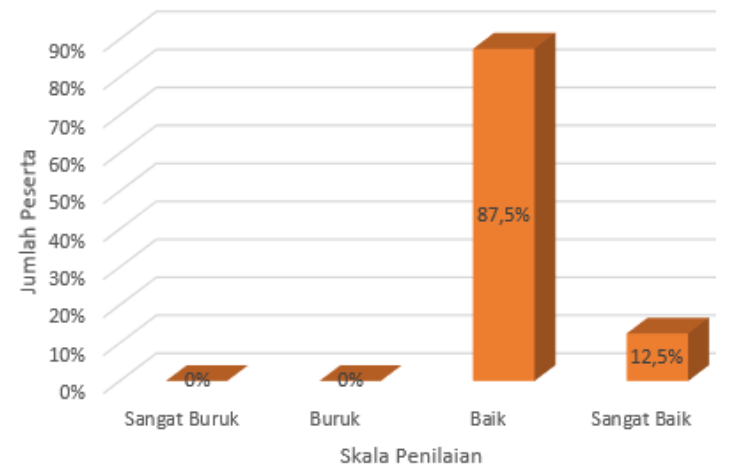

Gambar 5. Kepuasan peserta terhadap pemateri.

\section{B. KESIMPULAN DAN SARAN}

Tingkat kepuasan peserta pada pelatihan software Inventor dianalisa dengan menggunakan metode Kirkpatrick level 1 dimana hasil paling tinggi diskala penilaian baik dengan prosentase fasilitator mendapatkan nilai $87.5 \%$, fasilitas $87.5 \%$, pemateri $87.5 \%$ dan materi $87.5 \%$. Saran untuk pelatihan kedepannya bisa diselenggarakan dengan durasi yag lebih lama dan peserta mendapatkan buku paduan.

\section{DAFTAR PUSTAKA}

Jahidin, S. dan Manfaat, J., 2013, Rancang Bangun 3D Konstruksi Kapal Berbasis Autodesk Inventor untuk Menganalisa Berat Konstruksi, Jurnal Ternik Pomits, Vol.2, No.1.

Pinem, M.D., 2010, Analisis Struktur dengan Metode Elemen Hingga (Finite Element Method), Bandung: Rekayasa Sains.

Rozik, M.A., 2020, Perancangan dan Analisis Kekuatan Rangka Mesin Pengayak Pasir Mengggunakan Autodesk Inventor 2019, Skripsi, Univesitas 17 Agustus 1945, Surabaya, Indonesia.

Seprianto,D., 2011, Perancangan Alat Blending / Mixing Menggunakan Perangkat Lunak CAD Autodesk INVENTOR Professional 2010, Jurnal Austenit Vol.3 No.1.

Turner, W.C., Mize, J.H., Case, K.E., dan Nazementzm J.W., 1993, Introduction to Industrial and Systems Engineering, Prentice-Hall, Inc., New Jersey.

Hidayat, Jufriyanto, M., Wasiur, A., \& Ningtyas, A. H. P. (2020). Analysis Of Load Variations On ST 60 Steel Using Vickers Method. International 
Journal of Science, Engineering and Information Technology, 05(02), 5-9. https://doi.org/10.21107/ijseit.v5i1.89 40

Mustakim, Z., Yohana Purwaningtyas, F., Pahlawan, I. A., Djazuli, R. A., Anam, C., Dwi Anastasya, T., Arifah Chafsoh Rohmah, Z. N., Nuril Istighfar, M., \& Afif Lutfi, M. (2021). PELATIHAN PEMBUATAN SABUN TRANSPARAN BERBAHAN DASAR MINYAK JELANTAH. DedikasiMU (Journal of Community Service), 3(Juni), 936-943. https://doi.org/http://dx.doi.org/10.30 587/dedikasimu.v3i2.2683

Ningtyas, A. H. P., Ayunaning, K., Prambudiarto, B. A., Pahlawan, I. A., \& Maulana, I. (2021). IMPLEMENTASI PENGGUNAAN SOFTWARE AUTODESK INVENTOR DALAM MENINGKATKAN KOMPETENSI DALAM MENGGAMBAR TEKNIK PADA PELAJAR KEJURUAN. DedikasiMU (Journal of Community Service), 3(2), 925-935. http://dx.doi.org/10.30587/dedikasim u.v3i2.2680

Pahlawan, I. A., Arifin, A. A., Marliana, E., \& Irawa, H. (2021). Effect of welding electrode variation on dissimilar metal weld of 3161 stainless steel and steel ST41. Materials Science and Engineering, 1010. https://doi.org/10.1088/1757899X/1010/1/012001

Hidayat, H., Jufriyanto, M., \& Rizqi, A. (2021). Perancangan RCM (Reliability Centered Maintenance) Untuk Mengurangi Downtime Mesin Pembuat Botol (Studi Kasus PT IGLAS (Persero), Gresik). MATRIK : Jurnal Manajemen Dan Teknik Industri Produksi, 21(2), 157 - 164. doi:10.30587/matrik.v21i2.2038
Hidayat, H. (2020). Application of the EOQ (Economic Order Quantity) Method in Determining Chemical Supplies in PT. Semen Indonesia. International Journal of Science, Engineering and Information Technology, 5(1), 226230.

Hidayat, Jufriyanto, M., Wasiur, A., \& Ningtyas, A. H. P. (2020). Analysis Of Load Variations On ST 60 Steel Using Vickers Method. International Journal of Science, Engineering and Information Technology, 05(02), 5-9. https://doi.org/10.21107/ijseit.v5i1.89 40 